\title{
Microsieves for the detection of circulating tumor cells in leukapheresis product in non-small cell lung cancer patients
}

\author{
Menno Tamminga ${ }^{1}$, Lisa Oomens ${ }^{2}$, T. Jeroen N. Hiltermann ${ }^{1}$, Kiki C. Andree ${ }^{3}$, Arjan Tibbe ${ }^{2}$, \\ Joska Broekmaat ${ }^{2}$, Ed Schuuring ${ }^{4}$, Leon W. M. M. Terstappen ${ }^{3}$, Harry J. M. Groen ${ }^{1}$ \\ ${ }^{1}$ Department of Pulmonary Diseases, University Medical Center Groningen, University of Groningen, Groningen, The Netherlands; ${ }^{2}$ VyCAP, \\ Enschede, Groningen, The Netherlands; ${ }^{3}$ Department of Medical Cell BioPhysics, Faculty of Sciences and Technology, University of Twente, \\ Enschede, Groningen, The Netherlands; ${ }^{4}$ Department of Pathology and Medical Biology, University Medical Center Groningen, University of \\ Groningen, Groningen, The Netherlands \\ Contributions: (I) Conception and design: M Tamminga, TJN Hiltermann, A Tibbe, J Broekmaat, E Schuuring, HJM Groen; (II) Administrative \\ support: A Tibbe, J Broekmaat, HJM Groen; (III) Provision of study materials or patients: M Tamminga, HJM Groen, TJN Hiltermann; (IV) \\ Collection and assembly of data: M Tamminga, L Oomens, KC Andree, A Tibbe, J Broekmaat; (V) Data analysis and interpretation: M Tamminga, \\ TJN Hiltermann, HJM Groen, E Schuuring; (VI) Manuscript writing: All authors; (VII) Final approval of manuscript: All authors. \\ Correspondence to: Prof. Dr. Harry J. M. Groen. Department of Pulmonary Diseases, University Medical Center Groningen, Hanzeplein 1, P.O. Box \\ 30.0001, 9700 RB Groningen, The Netherlands. Email: h.j.m.groen@umcg.nl.
}

Background: Circulating tumor cells (CTC) in non-small cell lung cancer (NSCLC) patients are a prognostic and possible therapeutic marker, but have a low frequency of appearance. Diagnostic leukapheresis (DLA) concentrates CTC and mononuclear cells from the blood. We evaluated a protocol using two VyCAP microsieves to filter DLA product of NSCLC patients and enumerate CTC, compared with CellSearch as a gold standard.

Methods: DLA was performed in NSCLC patients before starting treatment. DLA product equaling $2 \times 10^{8}$ leukocytes was diluted to $9 \mathrm{~mL}$ with CellSearch dilution buffer in a Transfix CTC tube. Within 72 hours the sample was filtered with a $7 \mu \mathrm{m}$ pore microsieve and subsequently over a $5 \mu \mathrm{m}$ pore microsieve. CTC were defined as nucleated cells which stained for cytokeratin, but lacked CD45 and CD16. CellSearch detected CTC in the same volume of DLA.

Results: Of 29 patients a median of $1.4 \mathrm{~mL}$ DLA product (range, $0.5-4.1)$ was filtered (2\% of total product) successfully in $93 \%$ and $45 \%$ of patients using 7 and $5 \mu \mathrm{m}$ pores, respectively. Two DLA products were unevaluable for CTC detection. Clogging of the $5 \mu \mathrm{m}$ but not $7 \mu \mathrm{m}$ microsieves was positively correlated with fixation time $(\rho=0.51, \mathrm{P}<0.01)$. VyCAP detected CTC in 44\% $(12 / 27)$ of DLA products. Median CTC count per mL DLA was 0 [interquartile range (IQR): 0-1]. CellSearch detected CTC in 63\% of DLA products (median =0.9 CTC per mL DLA, IQR: 0-2.1). CTC counts detected by CellSearch were significantly higher compared with $\operatorname{VyCAP}(\mathrm{P}=0.05)$.

Conclusions: VyCAP microsieves can identify CTC in DLA product, but workflows need to be optimized.

Keywords: Diagnostic leukapheresis (DLA); circulating tumor cell (CTC); non-small lung cancer (NSCLC); liquid biopsy; biomarker; VyCAP microsieves

Submitted Sep 10, 2019. Accepted for publication Feb 28, 2020.

doi: $10.21037 /$ tlcr-19-413

View this article at: http://dx.doi.org/10.21037/tlcr-19-413 


\section{Introduction}

Circulating tumor cell (CTC) have prognostic value in nonsmall lung cancer (NSCLC) (1-5). However, in NSCLC CTC are detected in only $30 \%$ of metastatic NSCLC patients and in low frequencies of 1-2 CTC per $7.5 \mathrm{~mL}$ of blood (1-8). CTC are likely present in the majority of metastatic patients but the current available methods are only capable of screening limited volumes of blood $(9,10)$. As CTC have a similar density as mononuclear cells they can be extracted from the blood by means of a diagnostic leukapheresis (DLA), allowing the screening of a large volume of blood for CTC (10-13).

In the DLA product the CellSearch platform identifies CTC in higher frequencies and in more patients compared to peripheral blood (11-13). CellSearch uses positive immunomagnetic selection to extract the epithelial cell adhesion molecule (EpCAM) positive CTC. Due to the high numbers of leukocytes in the DLA product, which have non-specific interaction with the immunomagnetic particles targeting EpCAM, usage of the CellSearch platform in processing DLA is limited (11). VyCAP microsieves collect CTC by their relative size and rigidity, allowing for the detection of both EpCAM positive and negative cells (1-3). In addition, modified versions of these filters may allow isolation of single CTC for genomic analysis, or to perform functional tests in captured CTC (14-18). In this study we looked into the capability of VyCAP microsieves to filter the DLA product of NSCLC patients to enumerate CTC and compare the CTC counts per patient with those of CellSearch.

\section{Methods}

\section{Patient inclusion and clinical data}

Consecutive patients with proven NSCLC starting their treatment were prospectively included in an exploratory cohort. Patients who had an Eastern Cooperative Oncology Group Performance Status (PS) of 0-2 and did not use anticoagulation medication or suffer from clotting disorders were selected. All patients gave informed consent. The study was approved by the regional Medical Ethical Committee (NL55754.042.15) and registered in the Dutch trial register (NL5423), conducted in accordance with the Declaration of Helsinki (as revised in 2013).

\section{Diagnostic leukapheresis procedure}

DLAs were performed with the Spectra Optia ${ }^{\circledR}$ Apheresis
System using an intermediate density layer set (IDL) and software version 11 (Terumo BCT inc, Lakewood, CO, USA). The standard continuous MNC protocol was used with a packing factor of 4.5 , collection pump set to $1 \mathrm{~mL}$ per minute, hematocrit minus 3 percent points and a flexible inlet flow. Anticoagulant Citrate Dextrose Solution A (ACDA) was used for anticoagulation in a dilution of 1:11, further adjusted when aggregate formation was observed in the collection chamber.

We aimed to process the total blood volume (TBV) of the patient, as estimated with the formula of Nadler (19). DLA collection would be performed at a hematocrit around $5 \%$.

DLA procedure efficacy was measured by determining the percentage of lymphocytes that were captured compared to the number that passed through the machine (lymphocytes in DLA product divided by lymphocytes in blood that was processed).

\section{DLA product processing}

A DLA aliquot with a volume equaling that of $2 \times 10^{8}$ leukocytes was diluted with CellSearch Circulating Tumor Cell Kit Dilution Buffer (Menarini Silicon Biosystems, Huntingdon Valley, PA, USA) to $9 \mathrm{~mL}$ and transferred to a CTC-TVT Transfix tube (Cytomark, Buckingham, United Kingdom) and stored at room temperature for at least $24 \mathrm{~h}$. The sample was filtered within $72 \mathrm{~h}$ after completion of the DLA procedure using two VyCAP microsieves. This filtration in two steps was because of the experiences in the CTCTrap study, where CTC were lost and only a small volume of DLA could be filtered (13). Filtration and CTC detection occurred according to manufacturer instructions [version 2.1, September 2017 (20)]. Firstly, the whole DLA sample is filtered using a microsieve with pores of $7 \mu \mathrm{m}$ using a pressure of 30-250 mbar. Subsequently, the $7 \mu \mathrm{m}$ microsieve filtrate, collected in the waste compartment of the VyCAP disposable, was passed through a microsieve with $5 \mu \mathrm{m}$ pores at a pressure of 150-250 mbar. Immediately after filtration, the cells on the filter are stained with immunofluorescent labels using a permeabilization buffer, followed by the addition of a staining cocktail containing pan-cytokeratin CK-11 (PE, Cell Signaling Technology, \#5075S, clone C11), pan-cytokeratin AE1/AE3 (eFluor 570, eBioscience, 41-9003-82, clone AE1/ AE3), CD45 (APC, eBioscience, 17-0459-41/42, clone HI30) and CD16 (APC, BioLegend, \#302011, clone 3G8). Mounting medium containing DAPI was added followed by the addition of a cover slip. The microsieves were scanned and images of the cells on the microsieves were acquired. 


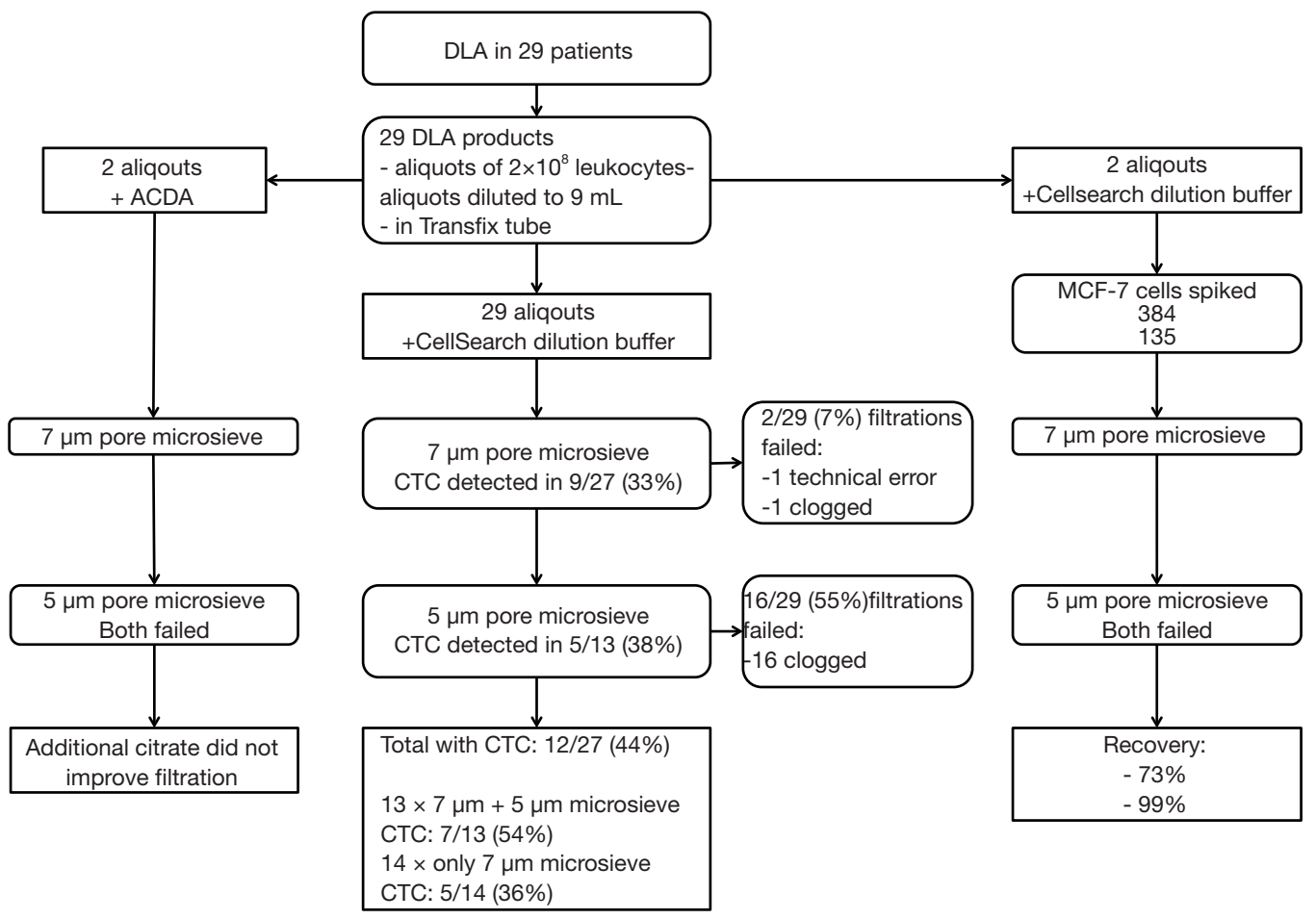

Figure 1 Processing diagnostic leukapheresis (DLA) samples for circulating tumor cells (CTC) filtration.

CTC, defined as cells expressing cytokeratins and containing a nucleus, but lacking CD45 and CD16 were counted. CTC counts are reported per mL DLA product.

Two samples which clogged were additionally labeled with CD41 (FITC, BD Pharmingham, cat\#557296) to detect platelets. In two patients a second DLA sample, in which ACDA was used to dilute the sample to $9 \mathrm{~mL}$ instead of CellSearch dilution buffer, was used to determine the influence of anticoagulants on the formation cell clusters and cell clumps in the DLA product.

\section{Comparison with CellSearch}

We detected CTC in DLA product with CellSearch as previously described (13). In short, a DLA product volume containing in total $2 \times 10^{8}$ leukocytes was diluted to $7.5 \mathrm{~mL}$ with CellSearch dilution buffer in a CellSave CTC tube (Menarini siliconbiosystems, Bologna, Italy). CellSearch would then be used to identify CTC according to manufacturer's instructions.

\section{Spiking tumor cells in DLA product}

To determine the recovery of tumor cells in DLA product,
DLA products of two patients were spiked with 384 and 135 MCF-7 cells that were manually counted before transferring these to the DLA sample. MCF-7 cells were exposed to the sample concentration of transfix for the same times as the DLA samples.

\section{Results}

\section{NSCLC patients and apheresis}

Twenty-nine NSCLC patients underwent an apheresis (Tables $S 1, S 2)$. The median estimated patient total blood volume was 5.2 L [interquartile range (IQR): 4.7-5.8], of which 4.6 L (IQR: 3.9-5.5 L) was processed in 102 minutes (IQR: 87-110). DLA procedures had a median efficacy (\%lymphocytes captured that passed through the machine) of 57\% (IQR: 55-65\%). The median volume of DLA product was $88 \mathrm{~mL}$ (IQR: 70-96), including $12 \mathrm{~mL}$ ACDA (IQR: 11-13) for anticoagulation. The total number of cells used for filtration was $2 \times 10^{8}$, which equaled a median volume of $1.4 \mathrm{~mL}$ (IQR: $1.1-2.3$ ) of DLA product, constituting $2.1 \%$ (IQR: $1.3-3.0 \%)$ of the total DLA product. CTC counts were determined using VyCAP filtration with $7 \mu \mathrm{m}$ followed by $5 \mu \mathrm{m}$ microsieves (Figure 1). 
Table 1 Diagnostic leukapheresis aliquots $(\mathrm{n}=29)$ from non-small cell lung cancer patients, dilution material and volumes and cell counts and final concentrations processed and filtered to detect CTC

\begin{tabular}{|c|c|c|c|}
\hline Variable & In blood & Vycap & CellSearch \\
\hline \multicolumn{4}{|l|}{ DLA aliquot } \\
\hline DLA product (mL) & 0 & $1.4(1.1-2.3)$ & $1.4(1.1-2.3)$ \\
\hline Leukocytes $\left(\times 10^{6}\right)$ & $67.5(57.0-87.8)$ & $200^{*}$ & $200^{*}$ \\
\hline Lymphocytes $\left(\times 10^{6}\right)$ & $12(8.3-15.8)$ & $74.0(50.8-107.9)$ & $74.0(50.8-107.9)$ \\
\hline Granulocytes $\left(\times 10^{6}\right)$ & $49.5(68.3-41.6)$ & $99.2(85.5-117.7)$ & $99.2(85.5-117.7)$ \\
\hline Platelets $\left(\times 10^{6}\right)$ & $2,197(1,646-2,891)$ & $2,549(1,964-4,282)$ & $2,549(1,964-4,282)$ \\
\hline Erytrocytes $\left(\times 10^{9}\right)$ & $35.3(31.4-36.9)$ & $0.9(0.5-1.3)$ & $0.9(0.5-1.3)$ \\
\hline \multicolumn{4}{|l|}{ Dilution material and volume } \\
\hline \multicolumn{4}{|c|}{ Concentrations per $\mathrm{mL}$ filtrate } \\
\hline Leukocytes $\left(\times 10^{6} / \mathrm{mL}\right)$ & $9.0(7.6-11.7)$ & 22.2 & 26.7 \\
\hline Lymphocytes $\left(\times 10^{6} / \mathrm{mL}\right)$ & $1.6(1.1-2.1)$ & $8.2(5.6-12.0)$ & $9.9(6.8-14.4)$ \\
\hline Monocytes $\left(\times 10^{6} / \mathrm{mL}\right)$ & $0.8(0.7-1.1)$ & $4.7(3.3-5.5)$ & $5.7(4.0-6.6)$ \\
\hline Granulocytes $\left(\times 10^{6} / \mathrm{mL}\right)$ & $6.6(5.6-9.1)$ & $11.1(9.5-13.1)$ & $13.2(11.4-15.7)$ \\
\hline Platelets $\left(\times 10^{6} / \mathrm{mL}\right)$ & $293.0(219-385)$ & $283(218-476)$ & $340(262-571)$ \\
\hline Erytrocytes (×10\%/mL) & $4.7(4.2-4.9)$ & $0.1(0.1-0.1)$ & $0.1(0.1-0.2)$ \\
\hline
\end{tabular}

*, standardized to a concentration of $200 \times 10^{6}$ leukocytes + maximal capacity of CellSearch.

\section{DLA filtration through 7 um sieves}

Out of 29 DLA products (Table 1) that were filtered with the $7 \mu \mathrm{m}$ pore microsieves, 93\% [27] succeeded. One sample failed to filtrate due to a technical issue and one due to clogging (processed at 72 hours after DLA). Failure of the sample to filtrate could not be associated with time between the DLA procedure and filtration (exposure time to fixative) or to cell counts in the DLA product (white blood cells, monocytes, lymphocytes, granulocytes, platelets, hematocrit). CTC were detected in 33\% (9/27) successfully filtered samples. CTC counts ranged from 0-3 CTC per mL DLA product (median =0, IQR: $0-0.7$ ).

\section{DLA filtration through 5 um filters}

Only $45 \%$ (13/29) of filtrations through the $5 \mu \mathrm{m}$ pore microsieves were successful, the others failed due to clogging of the filter. Neither cell counts in the DLA product nor DLA volume correlated to filtration failure. Only the time that DLA product was exposed to the fixative in the Transfix tube correlated positively with filtration failure $(\rho=0.51, P<0.01)$. Out of 29 samples filtered with $5 \mu \mathrm{m}$ pore microsieves, 19 were processed 24 hours after DLA. Seven of these nineteen failed (36\%). Seven samples were processed 48 hours after DLA, of which 6 failed (86\%). Two samples were processed at 72 hours and both clogged. CTC were detected in $38 \%(5 / 13)$ of successfully filtered samples. CTC count ranged from 0-1.8 CTC per mL DLA product (median =0, IQR: $0-0.9$ ).

\section{CD41 staining}

On several filters cellular aggregates were observed (Figure 2A). To study the presence of platelets immunofluorescent staining with CD41 was performed. Accumulation was observed in the 


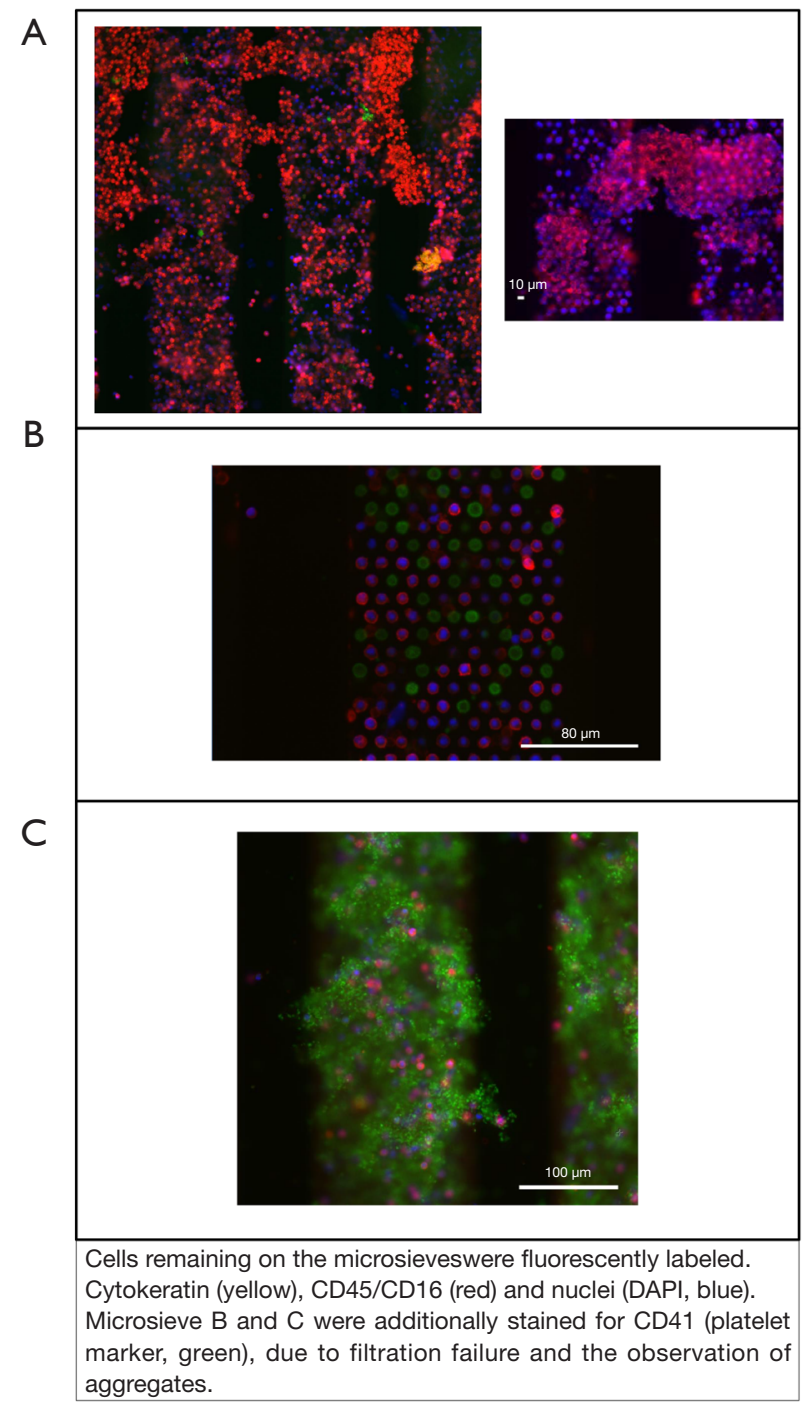

Figure 2 Clogged VyCAP microfilters: aggregates of cells (A), accumulation of CD41 (platelet marker) staining in pores of a sample processed without additional ACDA (B) and with additional ACDA (C).

pores of the filters (Figure 2B), indicating aggregation of platelets.

\section{Additional anticoagulant}

For two patients 2 DLA product samples of $2 \times 10^{8}$ leukocytes were investigated. Each patient had one sample diluted with CellSearch dilution buffer and one sample with ACDA for additional anticoagulation. The samples were processed at 24 hours after the DLA procedure. Both samples, with and without extra ACDA, could only be filtered using the $7 \mu \mathrm{m}$ pore microsieves. The $5 \mu \mathrm{m}$ pore filters clogged. The number of detected CTC did not differ. The additional ACDA did not prevent the formation of clumps and clusters (Figure 2C).

\section{Spiked CTC}

For both spiked samples, only the filtration with the $7 \mu \mathrm{m}$ microsieves was successful at 24 hours after DLA. Recovery percentage of MCF-7 cells was $73 \%$ and $99 \%$. 


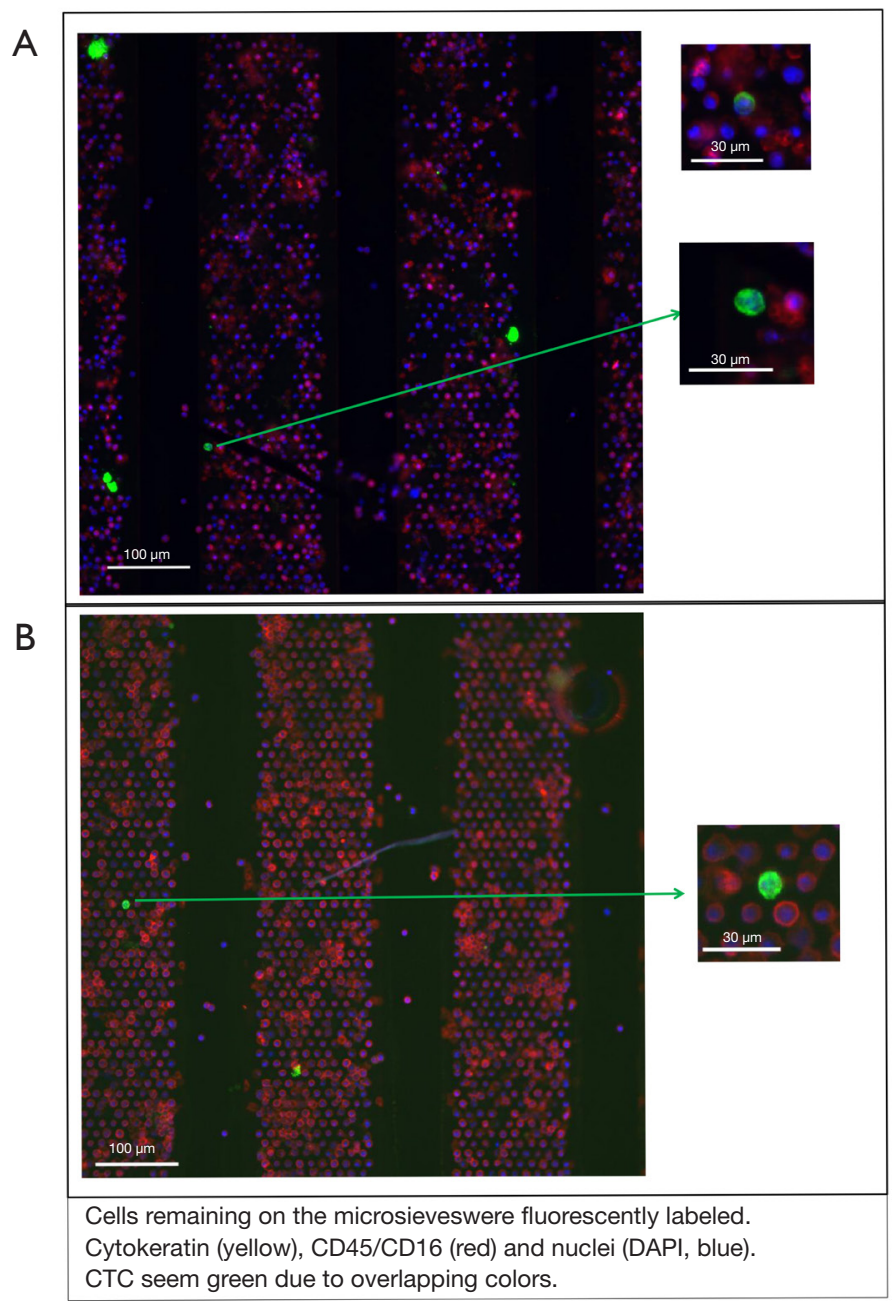

Figure 3 Circulating tumor cells identified on VyCAP filters.

\section{CTC detection}

In 27 out of 29 patients the DLA product was successfully filtered; in 2 patients filters could not be evaluated. Out of 27 filtered DLA products, 44\% [12] contained CTC (Figure $3 A, B$ ). The $7 \mu \mathrm{m}$ pore microsieves identified CTC in $33 \%(9 / 27)$ filtered DLA products. The $5 \mu \mathrm{m}$ pore microsieve successfully processed 13 samples, of which $38 \%$ $(\mathrm{n}=5)$ contained CTC. In the whole population, $41 \%$ had CTC detected (12/27). The combined CTC count from both filters in all patients ranged from 0-3 CTC per $\mathrm{mL}$ DLA product (median=0, IQR: $0-1$ ). Out of the 13 samples filtered by both filters, CTC were detected in 54\% (7/13).

\section{Comparison with CellSearch}

CellSearch detected CTC in 63\% (17/27) of the matched samples that successfully filtered with VyCAP (Table S3); Both samples that failed to filter had CTC detected by CellSearch. There was a low concordance between both methods. CellSearch detected CTC in 10 patients who were negative when processed by VyCAP, while VyCAP detected CTC in 5 patients that did not have CTC detected by CellSearch (Table S3). The proportion of patients with CTC detected did not differ significantly between CellSearch (63\%) and VyCAP (44\%, P=0.3). Combining the CellSearch and Vycap results, CTC were identified in $81 \%(22 / 27)$. Median CTC count detected by CellSearch was 0.9 per $\mathrm{mL}$ DLA product (IQR: 0-2.1). This was significantly higher than CTC counts detected by VyCAP $(\mathrm{P}=0.05)$.

\section{Discussion}

The VyCAP microsieve filtration system is developed for 
$7.5 \mathrm{~mL}$ blood samples to enumerate CTC. However, CTC are hardly detected in the peripheral blood of even advanced stage NSCLC patients. DLA has been shown to increase CTC yield (11-13). The current golden standard for CTC detection, the FDA cleared CellSearch system, is limited by the number of leukocytes it can process (11). In blood this poses no limitation, but in DLA product it severely restricts the volumes of DLA product that can be screened for CTC. Therefore, we attempted to use the VyCAP system to filter CTC from DLA product, which differentiates CTC based on their size and rigidity. We expected it to be less limited in the volume of DLA that could be processed. However, while the $7 \mu \mathrm{m}$ microsieves filtered the majority of samples, the $5 \mu \mathrm{m}$ VyCAP microsieves had problems with the formation of cell aggregates and the different composition of the DLA product, resulting in clogging of the microsieves. Fixation time was the only factor found to be associated with failure of samples to filter. The fixative is necessary to avoid the necessity to process the samples immediately after the DLA procedure. Although the underlying fixation process of the used fixative (Transfix) is unknown, it was demonstrated that the time the DLA samples was exposed to the fixative influences the ability of VyCAP microsieves to filtrate DLA product and detect CTC. Other parameters may also be of influence as well, e.g., the presence of debris in the Vycap disposable waste compartment, or temperature and leukapheresis composition. Though we found no association of filtration failure with platelet counts, we did observe platelets in the microsieves. Therefore, other anticoagulants may have beneficial effects on clogging. However, increasing the amount of ACDA for anticoagulation did not improve filtration. We believe that more research is required to optimize the protocol for processing DLA product with VyCAP microsieves before they can be effectively used.

While not yet optimized, we did observe a high recovery percentage of the spiked MCF-7 cells using only the $7 \mu \mathrm{m}$ microsieve. Yet CTC were detected in less patients with the microsieves (44\%) compared to CellSearch $(63 \%)$. The number of detected CTC was also significantly lower by VyCAP, reinforcing results found by Andree et al. (13). When combining CTC counts from CellSearch and $\mathrm{VyCAP}, \mathrm{CTC}$ detection increased to $81 \%$ of patients.

In conclusion, the used VyCAP filtration is not suitable for DLA product due to clogging of the $5 \mu \mathrm{m}$ microsieves. This appears to be caused by the time the DLA product is exposed to the fixative in the Transfix tubes. Workflows need to be optimized to be able to process DLA product and adjustments are necessary for filtration of larger DLA product volumes.

\section{Acknowledgments}

Funding: The authors are part of the CANCER-ID consortium which has received support from the Innovative Medicines Initiative (IMI) Joint Undertaking under grant agreement No 115749. VyCAP provided services at a discounted rate and the Cancer Research Funds provided a grant for partly covering the costs of filtration systems. The Funding sources had no influence on the gathering of data, interpretation of results or publication.

\section{Footnote}

Conflicts of Interest: All authors have completed the ICMJE uniform disclosure form (available at http://dx.doi. org/10.21037/tlcr-19-413). MT reports grants from IMI during the conduct of the study. TJNH reports grants from IMI during the conduct of the study; grants and other from AstraZeneca, Roche, BMS, other from Pfizer, Boehringer - Ingelheim, MSD outside the submitted work. KCA reports grants from IMI CANCER-ID project during the conduct of the study. ES reports grants from IMI during the conduct of the study; grants, personal fees and nonfinancial support from Biocartis, personal fees and nonfinancial support from BMS, Astrazeneca, Pfizer, Bayer, Illumina, Jansen Cilag, Agena Biosciences, Novartis, grants and non-financial support from Roche, grants from CC Diagnostics, Boehringer Ingelheim, personal fees from MSK/Merck outside the submitted work. LWMMT reports to be inventor of issued patents related to the CellSearch system (for example US patent: 6,365,362). HJMG reports grants from IMI during the conduct of the study. The other authors have no conflicts of interest to declare.

Ethical Statement: The authors are accountable for all aspects of the work in ensuring that questions related to the accuracy or integrity of any part of the work are appropriately investigated and resolved. All patients gave informed consent. The study was approved by the regional Medical Ethical Committee (NL55754.042.15) and registered in the Dutch trial register (NL5423), conducted in accordance with the Declaration of Helsinki (as revised in 2013).

Open Access Statement: This is an Open Access article distributed in accordance with the Creative Commons 
Attribution-NonCommercial-NoDerivs 4.0 International License (CC BY-NC-ND 4.0), which permits the noncommercial replication and distribution of the article with the strict proviso that no changes or edits are made and the original work is properly cited (including links to both the formal publication through the relevant DOI and the license). See: https://creativecommons.org/licenses/by-nc-nd/4.0/.

\section{References}

1. de Wit S, Rossi E, Weber S, et al. Single tube liquid biopsy for advanced non- small cell lung cancer. Int J Cancer 2019;144:3127-37.

2. de Wit S, Dalum G van, Lenferink ATM, et al. The detection of EpCAM+ and EpCAM- circulating tumor cells. Sci Rep 2015;5:12270-9.

3. Manicone M, Scaini MC, Rodriquenz MG, et al. Liquid biopsy for monitoring anaplastic lymphoma kinase inhibitors in non-small cell lung cancer: Two cases compared. J Thorac Dis 2017;9:S1391-6.

4. Krebs MG, Hou JM, Sloane R, et al. Analysis of circulating tumor cells in patients with non-small cell lung cancer using epithelial marker-dependent and -independent approaches. J Thorac Oncol 2012;7:306-15.

5. Hofman V, Long E, Ilie M, et al. Morphological analysis of circulating tumour cells in patients undergoing surgery for nonsmall cell lung carcinoma using the isolation by size of epithelial tumour cell (ISET) method. Cytopathology 2012;23:30-8.

6. Tamminga M, De Wit S, Hiltermann TJN, et al. Circulating tumor cells in advanced non-small cell lung cancer patients are associated with worse tumor response to checkpoint inhibitors. J Immunother Cancer 2019;7:173.

7. Tamminga M, Groen HJM. Circulating tumor cells are prognostic in SCLC, but still lack clinical application. Ann Oncol 2019;30:1031-3.

8. Tamminga $M$, de Wit S, Schuuring E, et al. Circulating tumor cells in lung cancer are prognostic and predictive for worse tumor response in both targeted- and chemotherapy. Transl Lung Cancer Res 2019;8:854-61.

9. Coumans FAW, Ligthart ST, Uhr JW, et al. Challenges in the enumeration and phenotyping of CTC. Clin Cancer Res 2012;18:5711-8.

10. Stoecklein NH, Fischer JC, Niederacher D, et al. Challenges for CTC-based liquid biopsies: low CTC frequency and diagnostic leukapheresis as a potential solution. Expert Rev
Mol Diagn 2015;7159:14737159.2016.1123095.

11. Fischer JC, Niederacher D, Topp SA, et al. Diagnostic leukapheresis enables reliable detection of circulating tumor cells of nonmetastatic cancer patients. Proc Natl Acad Sci U S A 2013;110:16580-5.

12. Fehm TN, Meier-Stiegen F, Driemel C, et al. Diagnostic leukapheresis for CTC analysis in breast cancer patients: CTC frequency, clinical experiences and recommendations for standardized reporting. Cytometry A 2018;93:1213-9.

13. Andree KC, Mentink A, Zeune LL, et al. Toward a real liquid biopsy in metastatic breast and prostate cancer: Diagnostic LeukApheresis increases CTC yields in a European prospective multicenter study (CTCTrap). Int J Cancer 2018;143:2584-91.

14. Andree KC, Abali F, Oomens L, et al. Self-Seeding Microwells to Isolate and Assess the Viability of Single Circulating Tumor Cells. Int J Mol Sci 2019;20:477.

15. Abali F, Stevens M, Tibbe AGJ, et al. Isolation of single cells for protein therapeutics using microwell selection and Surface Plasmon Resonance imaging. Anal Biochem 2017;531:45-7.

16. Wang C, Yang L, Wang Z, et al. Highly multiplexed profiling of cell surface proteins on single circulating tumor cells based on antibody and cellular barcoding. Anal Bioanal Chem 2019;411:5373-82.

17. Stevens M, Oomens L, Broekmaat J, et al. VyCAP's puncher technology for single cell identification, isolation, and analysis. Cytometry A 2018;93:1255-9.

18. Swennenhuis JF, Tibbe AGJ, Stevens M, et al. Self-seeding microwell chip for the isolation and characterization of single cells. Lab Chip 2015;15:3039-46.

19. Nadler SBSB. Prediction of blood volume in normal human adults. Surgery 1962;51:224-32.

20. Vycap. Filtration and staining protocol Optimized for whole blood samples. 2017. Available online: https:// www.vycap.com/inhoud/uploads/Filtration-and-stainingprotocol-2.1.pdf

Cite this article as: Tamminga $\mathrm{M}$, Oomens L, Hiltermann TJN, Andree KC, Tibbe A, Broekmaat J, Schuuring E, Terstappen LWMM, Groen HJM. Microsieves for the detection of circulating tumor cells in leukapheresis product in non-small cell lung cancer patients. Transl Lung Cancer Res 2020;9(4):10931100. doi: $10.21037 /$ tlcr-19-413 
Supplementary

Table S1 Characteristics of non-small cell lung cancer patients $(\mathrm{n}=29)$ undergoing apheresis

\begin{tabular}{|c|c|}
\hline Characteristics & Values \\
\hline Age (years) & $64 \pm 11$ \\
\hline \multicolumn{2}{|l|}{ Gender, n [\%] } \\
\hline Male & $19[66]$ \\
\hline Female & $10[34]$ \\
\hline \multicolumn{2}{|l|}{ ECOG PS, n [\%] } \\
\hline 0 & $16[55]$ \\
\hline 1 & $8[28]$ \\
\hline 2 & $4[14]$ \\
\hline 3 & $1[3]$ \\
\hline \multicolumn{2}{|c|}{ Smoking status, n [\%] } \\
\hline Smokers & $15[52]$ \\
\hline Previous & $8[21]$ \\
\hline Non smokers & $6[27]$ \\
\hline \multicolumn{2}{|l|}{ Stage, n [\%] } \\
\hline 1 & $2[7]$ \\
\hline II & $1[3]$ \\
\hline III & $4[14]$ \\
\hline IV & $22[76]$ \\
\hline
\end{tabular}

Histology, n [\%]

Adenocarcinoma

Squamous cell

6 [21]

Therapy line, $n$ [\%]

0

5 [16]

10 [35]

10 [35]

4 [14]

$\geq 3$

Treatment, n [\%]

Surgery

3 [10]

Chemo(radio)therapy

3 [10]

Immunotherapy

17 [59]

Targeted therapy

$6[21]$

Blood, median [IQR]

TBV (L)

$5.2[4.7-5.8]$

Processed volume $(\mathrm{L})$

$4.6[3.9-5.5]$

Percentage processed

$97 \%[46-100 \%]$

DLA product, median [IQR]

$\mathrm{mL}$

$88[70-96]$

ACDA

12 [11-13]

$\mathrm{mL}$ DLA processed

ECOG PS, Eastern Cooperative Oncology Group Performance Score; DLA, diagnostic leukapheresis procedure; SD, standard deviation; TBV, total blood volume; IQR, inter quartile range; ACDA, Anticoagulant Citrate Dextrose Solution A.

\begin{tabular}{lcc}
\multicolumn{3}{l}{ Table S2 Blood cell counts in DLA product per liter } \\
\hline Type blood cell & Mean & SD \\
\hline Red blood cells $\left(\times 10^{12} / \mathrm{L}\right)$ & 0.6 & 0.28 \\
Leukocytes $\left(\times 10^{9} / \mathrm{L}\right)$ & 135 & 76 \\
Lymfocytes $\left(\times 10^{9} / \mathrm{L}\right)$ & 51.8 & 22 \\
Monocytes $\left(\times 10^{9} / \mathrm{L}\right)$ & 29 & 10 \\
Granulocytes $\left(\times 10^{9} / \mathrm{L}\right)$ & 62 & 30 \\
Platelets $\left(\times 10^{9} / \mathrm{L}\right)$ & 1540 & 377 \\
Hemoglobin $(\mathrm{mmol} / \mathrm{L})$ & 0.91 & 0.28 \\
Hematocrit $(\%)$ & 0.07 & 0.04 \\
\hline
\end{tabular}


Table S3 Number of circulating tumor cells detected on Vycap microsieves and by CellSearch in non-small cell lung cancer patients ( $\mathrm{n}=29$ )

\begin{tabular}{|c|c|c|c|c|c|}
\hline Patient & $m L ~ D L A$ & CellSearch & Vycap total & Vycap $7 \mu \mathrm{m}$ pore & Vycap $5 \mu \mathrm{m}$ pore \\
\hline 2 & 1.00 & 12 & 3 & 3 & NA \\
\hline 3 & 2.99 & 0 & 3 & 2 & 1 \\
\hline 4 & 1.16 & 0 & 3 & 1 & 2 \\
\hline 6 & 1.09 & 1 & 2 & 2 & NA \\
\hline 7 & 1.40 & 3 & 1 & 1 & 0 \\
\hline 8 & 1.24 & 0 & 1 & 1 & NA \\
\hline 9 & 1.88 & 2 & 1 & 1 & NA \\
\hline 12 & 2.41 & 0 & 1 & 0 & 1 \\
\hline 13 & 0.98 & 0 & 0 & 0 & 0 \\
\hline 14 & 1.37 & 0 & 0 & 0 & 0 \\
\hline 15 & 1.86 & 1 & 0 & 0 & 0 \\
\hline 16 & 2.52 & 3 & 0 & 0 & 0 \\
\hline 17 & 0.54 & 2 & 0 & 0 & 0 \\
\hline 18 & 0.56 & 2 & 0 & 0 & 0 \\
\hline 19 & 1.09 & 0 & 0 & 0 & NA \\
\hline 25 & 2.16 & 6 & 0 & 0 & NA \\
\hline 26 & 1.23 & 2 & 0 & 0 & NA \\
\hline 27 & 2.37 & 4 & 0 & 0 & NA \\
\hline 28 & 2.17 & 26 & NA & NA & NA \\
\hline 29 & 2.74 & 1 & NA & NA & NA \\
\hline
\end{tabular}

